\title{
Enhancing Social Support System for Improving Food Security Among the Elderly Headed Household in Communal Areas of Zimbabwe
}

\author{
Kefasi Nyikahadzoi ${ }^{1}$, Byron Zamasiya ${ }^{2}$, George Alex Muchinako ${ }^{1} \&$ Charles Dziro ${ }^{1}$ \\ ${ }^{1}$ School of Social Work, University of Zimbabwe, Harare, Zimbabwe \\ ${ }^{2}$ Socio-economist, International Centre for Tropical Agriculture, Harare, Zimbabwe \\ Correspondence: Kefasi Nyikahadzoi, School of Social Work, University of Zimbabwe, P. Bag 66022, Kopje, \\ Harare, Zimbabwe. Tel: 263-772-240-861. E-mail: knyika@gmail.com
}

Received: March 24, 2013 Accepted: April 19, 2013 Online Published: May 14, 2013

doi:10.5539/jfr.v2n3p46 URL: http://dx.doi.org/10.5539/jfr.v2n3p46

\begin{abstract}
The study sought to establish factors that contribute towards food security among elderly headed households and then seek ways of enhancing them. The study was conducted in Mudzi District in Mashonaland East Province of Zimbabwe. Data was collected from wards 11, 12 and 16. The study used cross sectional household data collected using a structured questionnaire. Two measures of food security are used; namely household food insecurity access score and household dietary diversity score. The results showed that food insecurity access score was statistically higher for elderly headed household when compared to those headed by younger people. The study revealed that social capital, remittances, and off farm income generating projects can increase the elderly headed household's likelihood of being food secure. The study also showed that public assistance is not making a positive contribution towards food security of elderly headed household. This paper argues that it is important for government and civil society to promote social capital and support channels of remittances to elderly headed households in communal areas.
\end{abstract}

Keywords: food security, elderly, social support, dietary diversity, Zimbabwe

\section{Introduction}

According to Zimbabwe Statistical Agency, people aged above 60 years constitute $7 \%$ of the projected population of 12.4 million Zimbabweans (Zimbabwe National Statistical Agency, 2012). The majority of these people reside in communal areas. Studies by Huisman (2005) have shown that $51 \%$ of the chronically ill are the elderly people above the age of 60 . Huge medical bills, coupled with physical, functional and cognitive impairment make the elderly people vulnerable to food insecurity. Being food secure in our context implies having access to enough food for good health and active life through socially accepted ways. At minimum, food security should include readily availability of balanced diet and being assured to acquire acceptable food in a socially acceptable manner (Eicher \& Staatz, 1985). This rule out being food secure through emergency relief, scavenging, stealing or any other coping strategies (Woltil, 2012; Rukuni et al., 1990).

The elderly and elderly headed households are particularly vulnerable and prone to food insecurity (Kaseke, 1998). Given their deteriorating health, elderly people have unique dietary requirements that if not adequately met could exacerbate existing health complications. Inadequate food intake resulting in low feeding frequency with insufficient energy and other important nutrients may increase disease frequency. Quandt et al. (2001) note that hunger and food insecurity among the elderly, exacerbates acute chronic diseases and speed up the onset of degenerative diseases. Age related biological factors increase the older adults' risk of nutritional deficiencies (Quandt et al., 2001). These combine to decrease the quality and length of life among the elderly. Unless factors that enhance the elderly headed household's food security are known and ways of promoting them are devised, inadequate access to food and poor intake of nutritious food will continue to compromise the overall health of elderly people in communal areas. It is therefore important to investigate best practices used to enhance food security within the communal areas and then discuss how these can be out-scaled. This paper uses the institutional perspective to identify the social, economic, cultural and political factors that determine food security among the elderly people in rural areas. Once these factors are identified, the paper then uses theoretical 
arguments and empirical evidence, to show how civil society and government can promote food security among elderly headed households through enhancing factors that explain food security.

\subsection{Theoretical and Empirical Factors That Enhance Food Security}

Literature identified several factors that constrain elderly headed households from accessing enough food for active health life. Quandt et al. (2001) note that rural elderly have lower incomes and hence poor health than their counterparts in urban areas. They noted that the cost of food in rural areas is much higher and with limited selection in rural areas. According to Kaseke (1998), public assistance programs are not evenly distributed in rural areas and lack of knowledge of these limit rural elderly from accessing them. Even in cases where these facilities are available, distance to distributing points and lack of public transportation limit the elderly from accessing public assistance. As noted by Quandt et al. (2001) pride and reluctance to use services considered to be welfare as inhibiting elderly to secure food security.

Other studies found out that elderly people with social support systems such as family, and friends tend to be food secure (Quandt, 2001). In a study carried out in the USA, Woltil (2012) finds that having a spouse helps in preventing or reducing food insecurity. The author also identifies physical and cognitive health problems, limited resources, availability of reliable social support systems and the social environment as determinants of food security. Another research study on food security among elderly people in the USA finds that public and private food programs, personal savings, proximity of children and family members and food storage skills as major determinants of food security (Wolfe et al., 2012). The identified factors seem to be country specific and it is therefore important to identify factors that contribute to food security among the elderly headed households.

In Zimbabwe, most of the food insecure elderly headed households are in communal areas where they depend on peasant agriculture for own food production (Kaseke, 1998). Often, the elderly headed households own land and livestock and they use these for food production to enhance their food security (Kaseke et al., 1998). There are other factors that influence food production by the peasant farmers, these include the rainfall pattern and availability, the soils - some lands have been farmed for more than fifty years and cannot produce much without yield enhancing inputs like fertilizers which the peasants cannot easily afford (Kaseke et al., 1998). However, the availability of these inputs and even favorable agroecological conditions for agriculture are known to enhance the food security of non-elderly headed households. Kaseke et al. (1998) attributed this to the reduced ability to work in their own fields due to old age.

To mitigate the problem of food insecurity among vulnerable elderly headed households, the Government introduced food support programs like the free food distribution to the elderly (Kaseke et al., 1998). This does not however cover all the needy elderly headed households because of resource constraints on the Government part (Kaseke et al., 1998). Sometimes there is politicization of food distribution, corruption in the distribution system and ignorance of the bureaucratic system by the elderly households. Other government programs intended to benefit the elderly headed households include the Grain Loan Scheme (the elderly are not expected to repay the grain) and Public Assistance administered to the elderly aged 60+ years (Kaseke et al., 1998). With the Public Assistance system, it is assumed that the elderly face challenges of accessing offices of the Department of Social Services and other accompanying costs (transport and food for the elderly and their escorts) of collecting the meager amounts they receive under this program (Mbanje, 1991). It is thus important to empirically determine factors that enhance food security among the elderly headed households and then promote their functioning. This study uses the Ordinary Least Squares methods to investigate factors that determine food security among the elderly headed households in Zimbabwe.

\section{Research Methods}

The study was conducted in Mudzi district, which is in Mashonaland East Province of Zimbabwe. The study sites lie in natural farming region IV, which is semi-arid zone at an altitude of 500-900 metres above sea level. The major economic activity within the study area is predominantly farming. This natural farming region is an agro-ecologically low potential zone with high incidences of droughts and frequent long mid-season dry spells. The mean annual rainfall in Mudzi district ranges from 450 to $500 \mathrm{~mm}$ while the mean annual temperature is $23^{\circ} \mathrm{C}$. Due to the high aridity, maize yield in Mudzi district is about 0.5 tones/ha.

\subsection{Sampling and Data analysis}

Data for this study was collected from wards 11, 12 and 16. This study uses cross sectional household data from the baseline survey collected through structured interviews. Simple random sampling was used to select the wards and the households for interviewing from the lists that were provided by resident agricultural extension officers. During the survey, any selected households that were inaccessible were replaced by the next eligible 
household on the household list. Data collection for this study was done in December 2011 through face-to-face administration of questionnaires.

The data collection involved a household survey using a questionnaire with semi structured and structured questions. The survey collected information on household demographics and socioeconomic characteristics, 24-hour recall dietary assessment, dietary diversity, food consumption from major food groups, food insecurity, crop production and marketing. A sample of 120 households is actually greater than 74 , an apriori power analysis computed using $\mathrm{G}$ power (Franzel et al., 2007). It therefore means that the sample provides acceptable statistical power (that is 0.80 ) for moderate correlation $r=0.30$, at two tailed 0.05 level of significance.

\subsection{Conceptual/Empirical Framework}

$$
\mathrm{Y}_{1}=\mathrm{B}_{\mathrm{o}}+\mathrm{B}_{1} \mathrm{X}_{1}+\mathrm{B}_{2} \mathrm{X}_{2}+\mathrm{B}_{3} \mathrm{X}_{3}+\mathrm{B}_{4} \mathrm{X}_{4}+\ldots \ldots \ldots \ldots+\mathrm{e}
$$

$\mathrm{Y}_{1}$ is the dependent variable. In our case, it was in two forms; (a) Household Food Insecurity Score and (b) Household Dietary Diversity Score. The $\mathrm{X}_{\mathrm{i}}$ sare independent variables. These are listed in Table 1.

\subsubsection{Dependent Variables}

\section{(a) Household Food Insecurity Access Score (HFIAS)}

The HFIAS is a continuous measure of the degree of food insecurity (access) in the household in the past 30 days. According to Deitchler et al. (2011) the HFIAS reflects the three universal domains of household food insecurity that is anxiety about household food insecurity, insufficient quality and insufficient quantity of food supplies. This indicator captures the household's perception about their diet regardless of its nutritional composition (Coates, Swindale, \& Bilinsky, 2005). This food insecurity measure focuses on consumption related strategies and captures the household's behavioral and psychological responses to food insecurity or perceived food insecurity. The HFIAS is based on the assumption that households' experiences of food insecurity cause predictable reactions and responses that can be captured and quantified through a survey and then summarized into a score.

During the survey, the respondents were asked nine occurrence questions that consist of a generally increasing level of food insecurity. Specifically, the respondents were asked whether a specific condition associated with the experience of food insecurity ever occurred during the past 30 days. The questions included the occurrences of (i) worrying about food adequacy; (ii) eating the kinds of less preferred foods; (iii) eating limited variety; (iv) inability to eat less preferred foods; (v) eating smaller meal than needed; (vi) eating fewer meals in a day; (vii) failing to get food of any kind; (viii) sleeping at night hungry and; (ix) going the whole day or night without eating anything. Respondents were asked to either say yes $=1$ if event occurred or no $=0$ if the event did not occur. Each severity question is followed by a frequency-of-occurrence question, which asks how often a reported condition occurred during the previous four weeks. There are three response options representing a range of frequencies $(1=$ rarely, $2=$ sometimes, $3=$ often). As suggested by (Coates, Swindale, \& Bilinksy, 2007), the HFIAS is computed as follows: HFIAS (0-27) = summation of the occurrence multiplied by frequency-of-occurrence during the past 30 days for the nine food insecurity related conditions.

At a household level, a high HFIAS shows that a household is very food insecure while a low score shows that a household is less food insecure. The minimum HFIAS is zero and occurs when a household responds 'no' to all questions on the household food insecurity access scale. Alternatively, 27 is the maximum HFIAS and is obtained by summing up of all frequencies on the frequency on the frequency of occurrence questions when a household responds yes to occurrence question and 'often' as frequency of occurrence to the nine frequency-of-occurrence questions.

\section{(b) Household dietary requirements}

Dietary diversity is a qualitative measure of food consumptions that reflect household's access to wide variety of foods and it's a proxy of nutrient adequacy of the diet for household. It is meant to reflect, in a snapshot, the economic ability of a household to consume a variety of foods. That is, respondents were asked if they consumed the following food staff in the last twenty-four hours.

$\mathrm{A}=$ Cereals; $\mathrm{B}=$ Vitamin rich vegetables and tubers; $\mathrm{C}=$ Root and tubers; $\mathrm{D}=$ Dark green leafy vegetables; $\mathrm{E}=$ other vegetables; $\mathrm{F}=$ Vitamin $\mathrm{A}$ fruits; $\mathrm{G}=$ Other fruits; $\mathrm{H}=$ Meat, poultry, offal; $\mathrm{I}=$ Eggs; $\mathrm{J}=$ Fish and seafood; $\mathrm{K}=$ Pulses/legumes/nuts; $\mathrm{L}=$ Milk and milk products; $\mathrm{M}=$ Oil/fats; $\mathrm{N}=$ Sugar/honey.

Expected responses were yes $=1$ or no $=0$. 
A-M represents the food groups consumed by members of the household. Values for A through $\mathrm{M}$ will be either 0 or 1. Long reference periods were deliberately avoided as these could result in less accurate information due to imperfect recall. According to Swindale and Bilinsky (2005) the household dietary diversity score is the calculated as follows:

$$
\operatorname{HDDS}(0-14)=\operatorname{Sum}(\mathrm{A}+\mathrm{B}+\mathrm{C}+\mathrm{D}+\mathrm{E}+\mathrm{F}+\mathrm{G}+\mathrm{H}+\mathrm{I}+\mathrm{J}+\mathrm{K}+\mathrm{L}+\mathrm{M}+\mathrm{N})
$$

This reflects the total number of food groups consumed by members of the elderly households.

\subsubsection{Independent Variables}

Table 1 gives a summary of variables that determine food security among the elderly headed households.

Table 1. Independent Variables

\begin{tabular}{ll}
\hline Explanatory Variables & Description and type of variable \\
\hline Age & Age of the respondent (years) \\
Household size & Number of family members in a household \\
Farming experience & Number of years a household has been farming \\
Dependence ratio & Number of dependence over number in active group \\
Ownership cattle & Number of cattle owned \\
Total land size & Total size of land holding under cultivation 2008/9 \\
Labour & Number of members providing labour \\
Level of education & Years in school \\
Marital status & Married ( $1=$ Yes, $0=$ No) \\
Gender & Gender of household head ( 1 Yes, 0 No) \\
Sale of crops & Whether household sold $(1=$ Yes, $0=$ No) \\
Sale of livestock & Whether household sold livestock $(1=$ Yes, $0=$ No) \\
Extension & Visited by or visited an extension agent $(1$ yes, 0 if not $)$ \\
Remittances & Participated in research activities $(1$ yes, 0 if not $)$ \\
Social capital & Membership to a network (group, or association) \\
Public assistance & Whether household received public assistance $(1=$ yes, 0 if no) \\
Own an ox cart & Whether the household own an ox cart $(1$ yes, 0 if no) \\
\hline
\end{tabular}

\subsection{Data Analysis}

Data were analysed using STATA version 11.2. The descriptive analysis covers means, proportions and standard deviations to provide distribution across contextual variables. The results are presented in Table 2. Linear regression analysis was used to identify the factors that affect Household Food Insecurity Access Scale Score and the household dietary requirements. Before running the analysis, a test of multi-collinearity was conducted to determine if there were highly correlated independent variables. For those that were correlated, one of them was dropped from the model. The default cut off correlation value of 0.7 was used.

\section{Results}

Results of this study are presented in Tables 2, 3, 4 and 5. Tables 2 and 3 provide descriptive statistics of the dependent and independent variables respectively. Specifically, Table 2 compares food security situations of elderly and non-elderly headed households. Tables 4 and 5 provide determinants of household food insecurity access and dietary diversity respectively. 
Table 2. Comparison of food security between elderly and non-elderly headed households

\begin{tabular}{lllll}
\hline Variable & Elderly & Non elderly & tstatistics & $p$ value \\
\hline HIAS & 15.282 & 8.494 & -4.758 & $0.0000^{* * *}$ \\
& $(8,700)$ & $(6.563)$ & & \\
\hline HDDS & 5.282 & 6.321 & 3.500 & $0.0005^{* * *}$ \\
& $(1.773)$ & $(1.331)$ & & \\
\hline
\end{tabular}

Level of Significance: $* * *=1 \% ; * *=5 \% ; *=10 \%$.

Results in Table 2 show a significantly higher average household food insecurity score of 15.282 for elderly headed households compared with 8.494 for their counterparts. The mean household food insecurity access score is statistically higher for elderly headed households when compared to those households headed by younger people. The results also show that in a recommended basket of fourteen food items, the elderly and non-elderly headed households consume 5.282 and 6.321 respectively. The dietary diversity score is also statistically and significantly lower among elderly headed households compared to the younger household heads. According to Styen et al, (2006), lower dietary diversity scores imply that elderly headed households eat more of starch giving foods and less of protein rich foods. There is a high probability that of the elderly headed households consumed foods that are rich in carbohydrates but lack the essential micronutrients necessary for a health life.

Table 3. Socio economic characteristics of the sample

\begin{tabular}{lllll}
\hline Variable & Mean & Std. Dev & Minimum & Maximum \\
\hline Head's Marital status & 0.7692 & 0.4268 & 0.00 & 1.00 \\
Social capital & 0.2308 & 0.4268 & 0.00 & 1.00 \\
Dependency ratio & 1.0185 & 0.9060 & 0.00 & 4.00 \\
Head's Sex & 0.7949 & 0.4091 & 0.00 & 1.00 \\
Head Age & 69.5385 & 8.7895 & 60.00 & 99.00 \\
Household size & 5.8718 & 2.3190 & 2.00 & 12.00 \\
Household Labour & 3.1579 & 1.6689 & 0.00 & 7.00 \\
Head's Farming experience & 30.9167 & 10.6191 & 4.00 & 50.00 \\
Total land size & 3.1136 & 1.8992 & 0.20 & 8.00 \\
Sale of crops & 112.2821 & 200.4768 & 0.00 & 700.00 \\
Sale of livestock & 51.0256 & 112.7770 & 0.00 & 600.00 \\
Off farm activities & 11.7179 & 38.3659 & 0.00 & 192.00 \\
Remittances & 194.8718 & 431.0628 & 0.00 & 2000.00 \\
Extension & 0.5641 & 0.5024 & 0.00 & 1.00 \\
Number of cattle & 2.8718 & 2.7737 & 0.00 & 12.00 \\
Own ox cart & 0.5128 & 0.5064 & 0.00 & 1.00 \\
\hline
\end{tabular}

The average household head age of the elderly headed households is 69.5 with over $80 \%$ of them being males. The mean household size is 5.87 . About $70 \%$ of the elderly headed households have adequate household labour to work in their fields. The mean farming experience of the elderly is 50 years and the mean land size is 8 acres. On average, the most important source of income are remittances, followed by sale of crops then sale of livestock and lastly income from other non-farm activities such as selling of charcoal, mushrooms etc. The dependence ratio of 1.08 is slightly higher than 2.5 cited by Nyikahadzoi et al. (2012) in the same area for non-elderly headed households. This is contrary to Mutangadura's (2005) findings that elderly headed households have higher dependence ratio due to the high death rates among $15-35$ age group, which left many children under the care of grandparents. 
Table 4. Factors affecting household food insecurity access scores

\begin{tabular}{lllll}
\hline & Beta & Std. Error & $t$ & $\mathrm{p}$ value \\
\hline Constant & & 8.2240 & 4.0430 & $0.001^{* *}$ \\
Social capital & -0.037 & 5.3800 & -.1460 & 0.885 \\
Head's Education & -0.421 & 6.2190 & -1.8220 & $0.087^{*}$ \\
Marital status & 0.938 & 10.7360 & 1.7210 & 0.104 \\
Sex & -0.767 & 10.7730 & -1.4570 & 0.164 \\
Household size & -0.104 & 1.2370 & -0.4060 & 0.690 \\
Labour & -0.408 & 1.5730 & -1.4190 & 0.175 \\
Farming experience & -0.113 & 0.1590 & -0.5850 & 0.567 \\
Total land size & -0.177 & 1.2350 & -0.7220 & 0.481 \\
Sale of crops & -0.437 & 0.0110 & -1.6960 & 0.109 \\
Sale of livestock & 0.064 & 0.0180 & 0.2850 & 0.780 \\
Off farm activities & -0.15 & 0.0400 & -0.940 & 0.39 \\
Remittances & -0.395 & 0.0040 & -2.1370 & $0.048^{*}$ \\
Extension & 0.423 & 4.0370 & 1.8400 & $0.084^{*}$ \\
Public assistance & 0.413 & 10.3650 & 2.0390 & $0.058^{*}$ \\
Number of cattle & -0.081 & 0.6610 & -0.3750 & 0.712 \\
Own Ox cart & -0.297 & 4.5790 & -1.1440 & 0.269 \\
Dependency ratio & -0.086 & 1.744 & -0.4700 & 0.645 \\
\hline
\end{tabular}

$\mathrm{R}^{2}=0.56$; Level of Significance: $* * *=1 \% ; * *=5 \% ; *=10 \%$.

Variables that are known to reduce anxiety over likely occurrence food insecurity in a household include education level of the elderly head of the household, engagement in some off farm activities and remittances. Results in Table 4 show that public assistance and extension services are positively related to household food insecurity access scores. This probably implies that elderly headed households that already worry most about food insecurity status of the households tend to seek extension services and public assistance. Ownership of what Chipanhura (2010) describes as minimum bundle (that is scotch cart, and draft power), that delineates the poor and the rich does not impact on household food insecurity access of elderly headed households.

Table 5. Factors affecting Household dietary diversity

\begin{tabular}{lllll}
\hline Model & Coefficients & Std. Error & $t$-statistic & Sig. \\
\hline (Constant) & & 1.649 & 2.4170 & 0.028 \\
Education & 0.2690 & 1.0890 & 1.3780 & 0.187 \\
Marital status & -0.0030 & 0.8740 & -0.0160 & 0.988 \\
Dependency ratio & 0.0500 & 0.3480 & 0.2860 & 0.779 \\
household size & 0.0840 & 0.2450 & 0.3470 & 0.733 \\
Labour & 0.3790 & 0.3100 & 1.3890 & 0.184 \\
Farming experience & -0.3530 & 0.0310 & -1.9250 & $0.072^{*}$ \\
Total land size & 0.0270 & 0.2580 & 0.1110 & 0.913 \\
Sale of crops & 0.3220 & 0.0020 & 1.2990 & 0.212 \\
Sale of livestock & -0.1720 & 0.0040 & -0.7660 & 0.455 \\
Off farm activities & -0.0053 & 0.0090 & -0.3000 & $0.068^{*}$ \\
Remittances & 0.4390 & 0.0010 & 2.4620 & $0.026^{*}$ \\
Extension & -0.2820 & 0.8540 & -1.2040 & 0.246 \\
Public assistance & -0.4860 & 2.0910 & -2.4700 & $0.025^{*}$ \\
Number owned cattle & 0.3190 & 0.1370 & 1.4890 & 0.156 \\
Own ox cart & 0.1450 & 0.9160 & 0.5810 & 0.570 \\
Social capital & 0.4260 & 0.9950 & 1.9070 & $0.075^{*}$ \\
\hline
\end{tabular}

$\mathrm{R}^{2}=0.61$; Level of Significance: $* * *=1 \% ; * *=5 \% ; *=10 \%$. 
Variables that were found by Nyikahadzoi et al (2012) to be the main determinants of household dietary diversity among smallholders in communal areas of Zimbabwe are not significant in explaining diversity among the elderly headed households. These variables include availability of household labour, land size, ownership of draft power and farming experience. In fact, the results show that elderly headed households that get more involved in farming are nutritionally insecure. This confirms Ziliak and Gundersen's (2011) observations that as smallholders get older, they have less energy to work in the fields. Results in Table 5 show that they become more dependent on social networks, off farm activities and remittances. It is however surprising that public assistance is contributing negatively to household dietary diversity. The reason could be that public assistance is only provided to sustain life and one cannot buy adequate food.

Elderly headed households with high social capital are food secure. According to Putnam (1995) social capital helps the elderly heads of households to access information, influence, power and claims for support from others. Social capital allows the elderly headed households to have access to resources and services that would not otherwise be readily available to them. Putnam (1995) argues that social capital promotes network-based relations that are important in facilitating in-kind assistance for the elderly poor relatives. Remittances and other off farm income generating activities are a source of income for elderly headed households that help them to be nutritionally secure. The household uses the money to increase their dietary diversity by purchasing other food items that they do not produce.

\section{Discussion}

Discussions in this section are based on theoretical and empirical evidence to recommend how government and civil society can improve upon the variables that significantly explain food security among the elderly headed households. Variables that government and civil society can influence to improve food security among elderly headed households include social capital; off farm income generating activities, and remittances.

\subsection{Social Capital}

Social capital can increase the elderly headed households' likelihood of accessing various forms of social support during times of need. Martin et al. (2004) observe that households that know and trust neighbors may be more likely to borrow food. In our study area, social capital acquired over years of staying in a neighborhood or community is helping the elderly headed households to access food. In this regard, it is important therefore for civil society and government working in these communities to come up with innovative ways of supporting interpersonal relationships and supporting communities in which elderly people live in order to improve their access to food. We agree with Martin et al. (2004) that developmental agents that promote increased access to food could incorporate social capital by linking their services to neighborhood or community based activities. The government should encourage culturally oriented values such as "adopt-a-granny" concepts, which would see communities adopting elderly people in their communities.

\subsection{Promoting of off Farm Income Generating Projects}

Our results show that off farm income generating projects improve elderly people's dietary diversity. It is important therefore to introduce new income generating projects that are not labour intensive. These will include mushroom production, bee keeping and cattle rearing. Such technology should be age sensitive. According to Nyanguru (2008), elderly people in Zimbabwe are famous for making beads, mats and, woven baskets from local materials for income generation. Civil society could facilitate this effort through the provision of low interest micro finance schemes for the elderly to boost their business or even start new ones. Efforts should also be made to help industrious elderly in communal areas to find a market for their commodities. This is particularly important in making the elderly headed households to be self-sufficient and independent.

\subsection{Public Assistance}

Results from our study show that public assistance is not making a positive contribution towards improving food security of elderly headed households. Admittedly, public assistance has the potential to enhance the food security of elderly headed households especially if the amounts are substantial and transaction costs of accessing the assistance is low. Martin et al. (2004) argue that transaction costs of collecting public assistance can be too high compared to the benefit and hence discouraging. Transaction costs for accessing Public Assistance might include high transportation cost to the distribution point and long queues and time spent before being served. Therefore, to be effective in improving food security, public assistance interventions must deal with possible challenges that elderly people might face in accessing it. 


\subsection{Remittances}

Remittance is the single variable that promotes both food access and dietary diversity. In Zimbabwe, remittances are either from relatives working within the country or from those in the diaspora. For resident family members remitting money and other items to the elderly, government should consider introducing some tax concessions. This may include reducing their taxable income upon proof that they have an elderly person under their direct care.

Government should also create an enabling environment that promotes people in the Diaspora to remit money back home. These include reduction in remittance transaction costs and even extending financial services to rural areas where the bulk of the elderly live. The government and civil society can make efforts to broaden the number of people who remit money from the Diaspora by availing information on employment opportunities in other countries.

\section{Conclusion}

In this study we note that government policies that seek to improve agricultural production in communal areas fail to improve food security situations for elderly headed households. In fact, the results show that such an effort would make the elderly headed households even more vulnerable to food insecurity. For the elderly headed households, it has to be accepted that food security is not necessarily an agricultural problem. As people get older, household produce for own consumption becomes less important as a source of food security and income from other sources becomes more important.

The household and the local community are very important units for elderly people in rural areas. They provide social protection systems for elderly people in communal areas. At household level, the elderly can assess financial, material and human resources of other family members. There is also an urgent need for a paradigm shift in the focus of development through the provision of social services whereby Non Governmental Organizations and even government should provide services to the elderly as a method of instilling self-reliance and not to provide as a way of hand to mouth so that the services give explicit economic and social value to elderly people's contribution to their families and communities.

\section{Acknowledgements}

The authors would like to acknowledge the financial assistance received from the Centre for Applied Social Sciences for undertaking this study. We are also grateful to Maria Mahlangu for proof reading the manuscript.

\section{References}

Brownie, S. (2006). Why are individuals at risk of nutritional deficiency? Int. J. Nurs Pract. Apr., 12(2), 110-118. $\mathrm{http}: / / \mathrm{dx}$. doi.org/10.1111/j.1440-172X.2006.00557.x

Chipanhura, B. M. (2010). Poverty traps and livelihood options in rural Zimbabwe: Evidence from three districts. BWPI Working.

Coates, J., Swindale, A., \& Bilinsky, P. (2007). Household Food Insecurity Access Scale (HFIAS) for Measurement of Household Food Access: Indicator Guide (v3). Washington, DC: Food and Nutrition Technical Assistance II Project (FANTA-II Project). Academy for Educational Development (AED). Washington DC.

Deitchler, M., Ballard T., Swindale, A., \& Coates, J. (2011). Introducing a Simple Measure of Household Hunger for Cross-Cultural Use. USAID, Washington, DC. p. 5-6

Eicher, C., \& Staatz, J. (1985). Food Security Policy in Sub-Saharan Africa.Invited Paper for the XIXth Conference of the International Association of Agric.Economists. August 25-September 5, 1985, Malanga, Spain.

Franzel, F., Redfelder, E., Lang, A. G., \& Buchner, A. (2007). G*Power: A flexible Statistical power analyses program for social, behavioural and biomedical sciences. Behavior Research Methods, 39(2), 175-191. http://dx.doi.org/10.3758/BF03193146

Huisman, H. (2005). Contextualising Chronic exclusion: Female headed households in Semi Arid Zimbabwe. Royal Dutch Geographical Society, 96(3), 253-263.

Kaseke, E., Dhemba, J., Gumbo, P., \& Kasere, C. (1998). The state and dynamics of social policy practice and research in Zimbabwe. Harare, Zimbabwe.

Kaseke, E. (1998). Social Security Systems in Rural Zimbabwe. Harare, Friedrich Ebert Stiftung. 
Martin, K. S., Rogers, B. L., Cook, J. T., \& Joseph, H. M. (2004). Social Capital is associated with decreased hunger. Social science and medicine, 58, 2645-2654. http://dx.doi.org/10.1016/j.socscimed.2003.09.026

Mbanje, R. (1991). Social Security and the elderly in Zimbabwe. In Care of the elderly in Zimbabwe edited workshop proceedings of a workshop held in Harare, Zimbabwe.

Ministry of Health Tanzania. (1992). The Food and Nutrition Policy for Tanzania. Dar es Salaam, Tanzania Ministry of Health.

Mutangadura, G. B. (2005). Gender, HIV/AIDS and Rural Livelihoods in Southern Africa: Addressing the Challenges. A Journal of Culture And African Women Studies.

Nyanguru, A. C. (2008). Aging and the Elderly in the Family: A Changing African Scenario. In T. Maundeni, L. L. Levers, \& G. Jacques (Eds), Changing Family Systems: A Global Perspective. Gaborone: Bay Publishing.

Nyikahadzoi, K., Samati, R., Motsi, P. D., Siziba, S., \& Adekuhle, A. (2012). Strategies for improving the economic status of female headed households in eastern Zimbabwe: The case of adopting the IAR4D framework's Innovation platform. Journal of Social Development in Africa, 27(2).

Nyikahadzoi, K., Siziba, S., Mango, N., Mapfumo, P., Adekuhle, A., \& Fantubi, O. (2012). Creating food self reliance among smallholder farmers in Zimbabwe: Exploring the role of integrated agricultural research and development. Food Security: The Science, Sociology and Economics of Food Production and Access to Food, 4(4), 647-656.

Putnam, R. (1995). Bowling Alone: America's declining social capital. Journal of Democracy, 6(1), 65-78. http://dx.doi.org/10.1353/jod.1995.0002

Quandt, S. A., Arcury, T. A., MacDonald, J., Bell, R. A., \& Vitolins, M. Z. (2001). Meaning and management of food security among rural elderly. Journal of Applied Gerontology, 20(3), 356-376. http://dx.doi.org/10.1177/073346480102000307

Rukuni, M., Mudimu, G., \& Jayne, T. (1990). Food Security Policies in the SADCC Region. Proceedings of the $5^{\text {th }}$ Annual Conference on Food Research in Southern Africa. Harare,University of Zimbabwe.

Styen, N. P., Nel, J. H., Nantel, G., Kennedy, G., \& Labadarios, D. (2006). Food Variety and Dietary Diversity Scores in children are they good indicators of dietary adequacy. Public Health Nutrition, 9(5), 644-650.

Swindale, A., \& Bilinsky, P, (2006). Development of a universally applicable household food insecurity measurement tool: process, current status, and outstanding issues. Journal of Nutrition, 136(5), 1449S-1452S.

Swindale, A., \& Bilinsky, P. (2005). Household dietary diversity score (HDDS) for measurement of household food access: indicator guide. Washington: Food and Nutrition Technical Assistance.

Woltil, J. (2012). The Impact of Emotional Social Support on Elders'Food Security. Scholarly Papers Submitted by Students in Sociation Today.

Ziliak, J. P., \& Gundersen, G. (2011). Food insecurity among the older adults. Drive to end hunger project report.

Zimbabwe National Statistical Agency. (2012). Census 2012 Preliminary Report. Harare, Zimbabwe National Statistical Agency. 